\title{
Study of Change in Physico-Chemical Parameters by Treatment of Sludge from Common Effluent Treatment Plant (CETP) with Earthworms
}

\author{
S. Maheshwari†*, P. Kriplani*, A. S. Jethoo**, P. Kumar** and M. Khwairakpam*** \\ *Department of Chemistry, Govt. Women Engineering College Ajmer-305002, Rajasthan, India \\ **Department of Civil Engineering, Malaviya National Institute of Technology, Jaipur-302017, Rajasthan, India \\ ****Department of Civil Engineering, National Institute of Technology, Meghalaya-793003, India \\ Corresponding author: S. Maheshwari; seemamaheshwari@gweca.ac.in
}

Nat. Env. \& Poll. Tech.

Website: www.neptjournal.com

Received: $22-10-2020$

Revised: $20-11-2020$

Accepted: 09-01-2021

\section{Key Words:}

Common effluent treatment

plant sludge

Eudrilus eugeniae

Vermicompost

Cow dung

Sawdust

Total nitrogen

Phosphorus

\begin{abstract}
One of the most vital problems of environmental protection concern is that of solid waste disposal. This problem continues to grow with the growth of population and the development of industries. The Common Effluent Treatment Plant (CETP) already establishes itself as a service to society at large, contributing towards a cleaner environment. However, the inappropriate disposal of CETP's hazardous sludge can cause serious environmental problems. The sludge if sent for landfilling may cause groundwater contamination, changing the soil fertility parameters as well. The research presented here is carried out to explore the ability of an epigeic earthworm Eudrilus eugeniae to transform the sludge produced from CETP into a value-added product i.e., vermicompost. In this study, six samples of feed mixture were used with different ratios of CETP sludge, cow dung, and sawdust. Physico-chemical parameters such as $\mathrm{pH}$, Electrical Conductivity (EC), Volatile Solids (VS), Total Nitrogen (TN), Nitrate Nitrogen $\left(\mathrm{NO}_{3}{ }^{-} \mathrm{N}\right)$, Ammonium Nitrogen $\left(\mathrm{NH}_{4}{ }^{+}-\mathrm{N}\right)$ were characterized to analyze the quality of the compost formed. All these parameters are in the agreement with recommended standards of mature compost. The result shows that vermicomposting technique when used, epigeic earthworm Eudrilus eugeniae can work as a favorable alternative solution for the disposal of CETP sludge.
\end{abstract}

\section{INTRODUCTION}

Over the last few years, the problem of efficient disposal and management of organic solid wastes has become more rigorous due to the rapid increase in population, intensive agriculture, and industrialization. To maintain a cleaner environment, waste disposal has become an issue of vital importance. Due to rapid industrialization and urbanization, the consumption of water also increases resulting in the generation of a large quantity of wastewater (Suthar 2012, Tchobanoglous et al. 1993). The effluent treatment plants are good alternatives as they include the physical, chemical, and biological processes for the treatment of wastewater discharged from the industries and commercial complexes. Wastewater contains dissolved organic compounds which get suspended during primary and secondary treatment of wastewater generating sludge (Bantacut \& Aulia 2019). In recent years, the methodology of sludge management has shifted from conventional methods such as incineration and landfill to the recent concept of sludge-conversion into nutrient-rich products (Maheshwari et al. 2019). Although various physical, chemical, and microbiological methods of disposal of organic solid waste are currently in use, these methods are time-consuming and costly. In this context, vermicomposting is an eco-friendly technology for the conversion of various kinds of organic waste into vermicompost. It is a biological process in which earthworms are introduced in the sludge to convert the organic wastes into humus-like material known as vermicompost. Epigeic earthworm species are able to consume different types of organic wastes which include sewage sludge, industrial sludge, animal dung, agricultural residues, household wastes, and industrial waste (Yadav \& Garg 2009). According to a group of researchers (Dominguez \& Edwards 1997, Saradha 1997), vermicomposting is mesophilic $\left(10-32^{\circ} \mathrm{C}\right)$ and it involves the combined synergetic action of earthworm and microorganism for decomposition of waste and produces nutrient-rich compost. Vermicomposting of industrial sludge was carried out by decomposition of solid textile mill sludge (STMS) mixed with poultry droppings by using epigeic earthworm Eisenia fetida. (Kaushik \& Garg 2004, Lee 1992, Neuhauser et al. 1998, Reinecke et al. 1992). A group of researchers (Edwards 1999, Edwards \& Arancon 2004, Elvira et al. 1996) explained the bioconversion of solid paper-pulp mill sludge and primary sewage sludge with earthworms $E$. andrei. The results indicated that the loss of total carbohydrate was higher in the presence of earthworms (80\%) than in their 
absence (72\%). Begum and Harikrishna (2010) studied the growth of E. fetida and decomposition of municipal sewage sludge for a period of 60 days (Begam \& Harikrishna 2010, Bishop \& Godfrey 1983, Canelles et al. 2002, Edward 1995). A six-month pilot-scale study was carried out on vermicomposting of sludge from paper mill using earthworm species $E$. andrei. The vermicompost obtained at the end of the experiment was rich in nutrients like nitrogen, phosphorus, potassium and had good water holding capacity, high humic acid content, and low levels of heavy metals. (Elvira et al. 1997, Garg \& Kaushik 2005, Hemalatha 2012, Kalamdhad et al. 2012). Although some of the work has been explored on vermicomposting of sewage sludge and different industrial sludge like textile mill sludge, pulp, and paper mill sludge, food industry sludge, and distillery sludge using different earthworm species (Atiyeh et al. 2002, ROU 2007, Selladurai et al. 2009, Sinha et al. 2008, Yadav \& Garg 2011). The study of vermicomposting of CETP sludge is still in infancy, so the purpose of the present work is the production of stabilized, matured compost by using CETP sludge and to evaluate physico-chemical and stability parameters of industrial solid waste.

\section{MATERIALS AND METHODS}

Earthworm species Eudrilus eugeniae was selected for this study because E. eugeniae is a major waste eater and biodegrading earthworm species. Earthworm species used in this study were collected from Morarka Organic Food Ltd. Jaipur Rajasthan. The bulking agent sawdust was collected from a woodshop and cow dung collected from the H-Quarters at MNIT Jaipur. CETP sludge was collected from CETP Bhiwadi District Alwar Rajasthan. (Fig. 1).

The experimental work was carried out with a different percentage of compost material i.e. CETP sludge, cow dung, and sawdust using earthworm species E. eugeniae (Fig. 2). The initial parameters of different ingredients for composting of sludge with sawdust and cow dung with different combinations are given in Table 1 and different percentages of compost material i.e. CETP sludge, cow dung, and sawdust is given in Table 2 .

The objective of this study was to identify the most suitable combination of sludge, cow dung, and sawdust using earthworm species E. eugeniae. The experiment was conducted in a plastic container with a capacity of 20 L. 20 holes along the circumference and 15 holes $(0.5 \mathrm{~cm}$ diameter $)$ at the bottom of the container were drilled to provide aeration and drainage. Reactors containing different percentages of sludge, cow dung, and sawdust were kept at room temperature. Each reactor was inoculated with earthworm biomass of $100 \mathrm{gm}$. The moisture content of feed in each reactor was maintained at $60-80 \%$, throughout the study period by the sprinkling of an adequate quantity of water. Separate reactors were placed with the same conditions and combination of material but without earthworm to evaluate the efficiency of the process.

\section{Sampling and Sample Analysis}

About $150 \mathrm{~g}$ of homogenized wet samples of the feedstock was analyzed before the start of the experiment referred to as zero-day, then samples were analyzed after every six days interval. The zero-day refers to the substrate taken out before earthworm inoculation. Sample analysis was carried out at PHE Laboratory, civil engineering department MNIT Jaipur and Agricultural Research lab Durgapura Jaipur. The physico-chemical and biological parameters were analyzed, by the methods described in the standard methods for the examination of wastewater (APHA, AWWA \& WEF 1999).

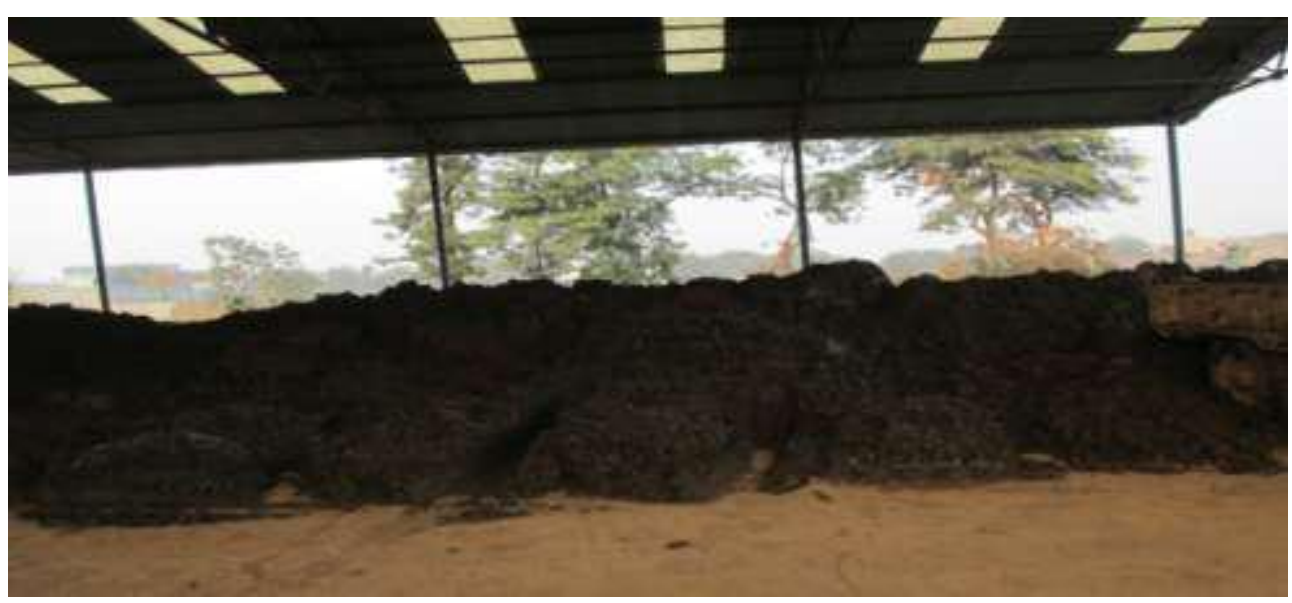

Fig. 1: CETP sludge storage site at CETP Bhiwadi. 


\section{Physico-Chemical Analysis}

Various physico-chemical studies have been carried out such as $\mathrm{pH}$, electrical conductivity (EC), volatile solids (VS), Total Nitrogen (TN), Nitrate nitrogen $\left(\mathrm{NO}_{3}{ }^{-} \mathrm{-N}\right)$, Ammonium nitrogen $\left(\mathrm{NH}_{4}{ }^{+}-\mathrm{N}\right)$, etc. After the completion of the vermicomposting process, earthworm biomass was measured. The earthworms were separated from the compost by putting compost in sunlight for few minutes. The earthworms tend to move downwards away from the sunlight towards the bottom. When most of the earthworms move down, the upper compost free from earthworms was separated. Later on, a small part of compost with earthworm remained, which was separated by hand sorting method.

\section{Vermireactors with Different Feed Mixture Percentage}

R1 Vermicomposting of Sludge with Cow dung (CD) and Sawdust (SD) (80:20:00)

R2 Vermicomposting of Sludge with Cow dung (CD) and Sawdust (SD) (50:50:00)

R3 Vermicomposting of Sludge with Cow dung (CD) and Sawdust (SD) (50:25:25)

R4 Vermicomposting of Sludge with Cow dung (CD) and Sawdust (SD) (70:30:00)

Table 1: Initial Characteristics of Waste Material

\begin{tabular}{|llll|}
\hline Parameters & Sludge & Cow Dung & Saw Dust \\
\hline $\mathrm{pH}$ & 8.44 & 8.3 & 6.95 \\
E.C. $(\mathrm{mS} / \mathrm{cm})$ & 2.73 & 1.01 & 0.83 \\
$\mathrm{TKN}(\%)$ & 1.22 & 1.56 & 0.89 \\
$\mathrm{NH}_{4}-\mathrm{N}(\mathrm{g} / \mathrm{Kg})$ & 0.092 & 0.158 & 0.041 \\
$\mathrm{NO}_{3}-\mathrm{N}(\mathrm{g} / \mathrm{Kg})$ & 0.877 & 0.332 & 0.121 \\
$\mathrm{TN}(\mathrm{g} / \mathrm{Kg})$ & 13.08 & 15.93 & 9.02 \\
\hline
\end{tabular}

R5 Vermicomposting of Sludge with Cow dung (CD) and Sawdust (SD) (40:40:20)

R6 Vermicomposting of Sludge with Cow dung (CD) and Sawdust (SD) (30:30:40)

Each Reactor contained a Control (i.e. CR)

\section{RESULTS AND DISCUSSION}

\section{pH}

The variations of $\mathrm{pH}$ in all the six vermireactors during the period of 24 days of vermicomposting are shown in Fig. 3 (with worms) and Fig. 4 (without worms). There is an initial increase in all vermireactors namely R1, R2, R3, R4, $\mathrm{R} 5, \mathrm{R} 6$ and decreased in the later phase of composting. The initial increase in $\mathrm{pH}$ means the participation of microbes in the degradation representing aerobic metabolism which produces the basic hydroxides and subsequent increase in $\mathrm{pH}$ in the initial phase of decomposition. In all the vermireactor initially, $\mathrm{pH}$ increased up to 6 days except $\mathrm{R} 6$ in which pH increased up to 12 days and later on starts decreasing. The reduction of $\mathrm{pH}$ in vermireactors was observed more than their controls. This could be because earthworm guts release

Table 2: Different percentage of compost material i.e. CETP sludge, cow dung, and sawdust (in brackets indicates the percentage content in initial feed mixer)

\begin{tabular}{|llll|}
\hline Vermireactors & $\begin{array}{l}\text { CETP } \\
\text { Sludge }(\mathbf{k g})\end{array}$ & $\begin{array}{l}\text { Cow dung } \\
(\mathbf{K g})\end{array}$ & $\begin{array}{l}\text { Saw dust } \\
(\mathbf{k g})\end{array}$ \\
\hline R1 & $1.2(80)$ & $0.3(20)$ & $0(0)$ \\
R2 & $0.75(50)$ & $0.75(50)$ & $0(0)$ \\
R3 & $0.75(50)$ & $0.375(25)$ & $0.375(25)$ \\
R4 & $1.05(70)$ & $0.45(30)$ & $0(0)$ \\
R5 & $0.60(40)$ & $0.60(40)$ & $0.30(20)$ \\
R6 & $0.525(35)$ & $0.525(35)$ & $0.45(30)$ \\
\hline
\end{tabular}

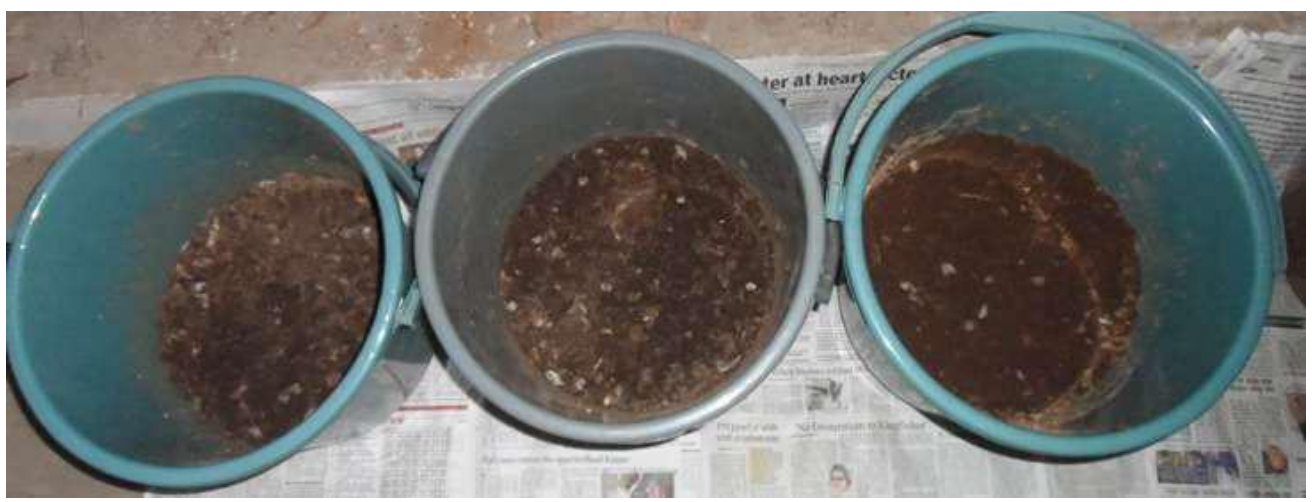

Fig. 2: Vermicompost reactors used in the experiment. 
the neutral $\mathrm{pH}$. The $\mathrm{pH}$ in vermireactor $\mathrm{R} 2$ was observed at 7.35 near-neutral $\mathrm{pH}$ as compared to all vermireactors and their controls (without worms).

\section{Electrical Conductivity (EC)}

Electrical conductivity is the ability to carry an electrical charge, a measure of the soluble salt content of vermicompost. EC value reflects the degree of salinity during composting, indicating its possible phytotoxicity effects on the growth of plants if applied to the soil. The variations of EC in different vermireactors during the period of 24 days of vermicomposting are illustrated in Fig. 5 (with worms) and Fig. 6 (without worms). Initially increase in EC was observed up to the $18^{\text {th }}$ day with its subsequent decrease. The increase in EC is due to the degradation of organic matter, releasing minerals such as $\mathrm{Ca}, \mathrm{Mg}, \mathrm{K}$, and $\mathrm{P}$ is available from. The decrease of EC in the later phase of composting is due to the precipitation of mineral salts. The highest EC was observed in vermireactor $\mathrm{R} 2$ among all the vermireactors. The augmentation in EC was more in vermireactors (with worms) than the control (without worms).

\section{Total Nitrogen (TN)}

Total nitrogen content was increased throughout the vermicomposting period as shown in Fig. 7 (with worms) and Fig. 8 (without worms). Initial total nitrogen values were 14.33 g. $\mathrm{kg}^{-1}, 18.44$ g.kg ${ }^{-1}, 12.86$ g. $\mathrm{kg}^{-1}, 14.35$ g. $\mathrm{kg}^{-1}, 12.89$ g. $\mathrm{kg}^{-1}, 11.47$ g. $\mathrm{kg}^{-1}$ in vermireactors R1, R2, R3, R4, R5, R6 respectively. After 24 day of vermicomposting, total nitrogen content values were 25.34 g. $\mathrm{kg}^{-1}, 36.72$ g.kg ${ }^{-1}, 24.12$ g. kg ${ }^{-1}$, 21.38 g.kg ${ }^{-1}, 22.75$ g.kg-1, 18.56 g.kg-1 in vermireactors R1, R2, R3, R4, R5 and R6 respectively. According to Bishop and Godfrey (1983), nitrogen-fixing bacteria might have also contributed to the increase in $\mathrm{TN}$ in the later stage of composting. It is suggested that along with $\mathrm{N}$ release from compost material, earthworms increase nitrogen levels by releasing mucus and by accumulating excretory products, body fluids, and other biological fluids rich in nitrogen. Decaying tissues of dead worms is yet another factor for TN to hike to a significant amount. The highest total nitrogen was observed in vermireactors $\mathrm{R} 2$ in 24 days of vermicomposting.

\section{Ammonium Nitrogen $\left(\mathrm{NH}_{4}{ }^{+} \mathrm{N}\right)$}

Ammonium concentration is an important indicator of compost stability and maturity. Mostly, ammonium nitrogen present during aerobic composting was derived from the rapid decomposition of waste. When ammonium concentration decreases and nitrate appears in composting material, it is considered ready to be used as compost. It has been noted that the absence or decrease in $\mathrm{NH}_{4}^{+} \mathrm{N}$ is an indicator of a high-quality composting process (Hirai et al. 1983).

The ammonium nitrogen concentrations decrease in both vermireactors with worms and without worms throughout the period of experimentation as shown in Fig. 9 and Fig. 10 respectively. The maximum decrease in ammonium nitrogen concentration was observed in vermireactor R4 from the initial level of $0.202 \mathrm{~g} . \mathrm{kg}^{-1}$ to $0.0796 \mathrm{~g} . \mathrm{kg}^{-1}$ and the minimum decrease was observed in vermireactor $\mathrm{R} 1$ from an initial level of $0.0693 \mathrm{~g} \cdot \mathrm{kg}^{-1}$ to $0.0336 \mathrm{~g} \cdot \mathrm{kg}^{-1}$. The concentration of ammonium nitrogen decreases due to its conversion to nitrate nitrogen. Yadav and Garg (2009) reported that decreasing ammonium nitrogen concentration is due to Nitrate Nitrogen formation and volatilization as ammonia at high $\mathrm{pH}$.

\section{Nitrate Nitrogen $\left(\mathrm{NO}_{3}{ }^{-}-\mathrm{N}\right)$}

During composting, nitrate nitrogen increases regularly due to the conversion of ammonium nitrogen into nitrate nitrogen

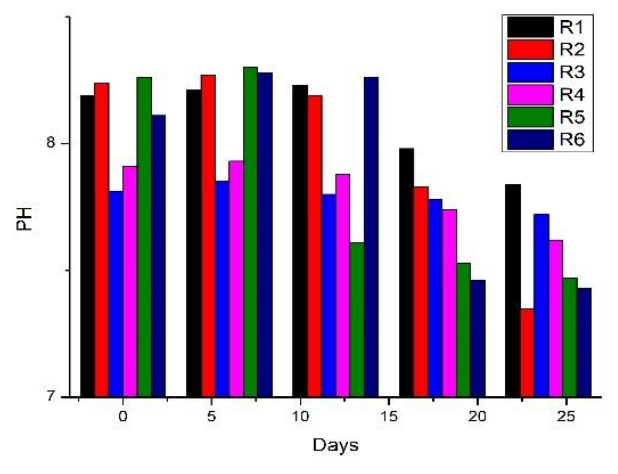

Fig. 3: Variation of $\mathrm{pH}$ in vermireactors (with worms).

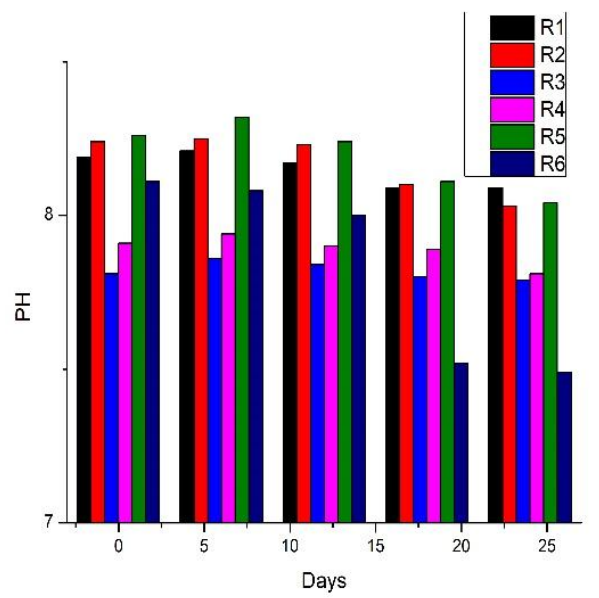

Fig. 4: Variation of $\mathrm{pH}$ in vermireactors (without worms). 


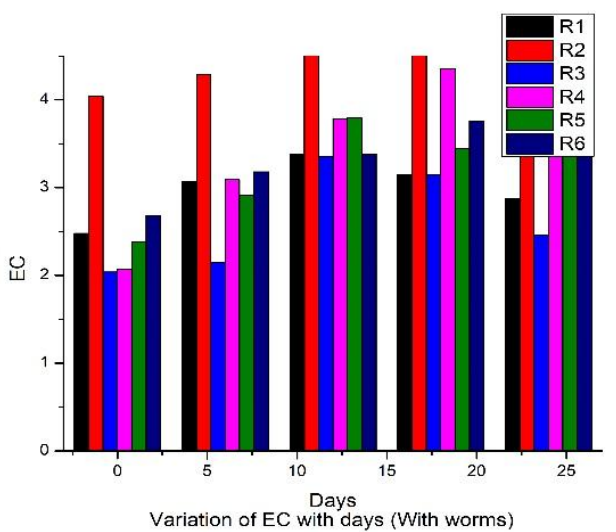

Fig. 5: Variation of electrical conductivity in vermireactors (with worms).

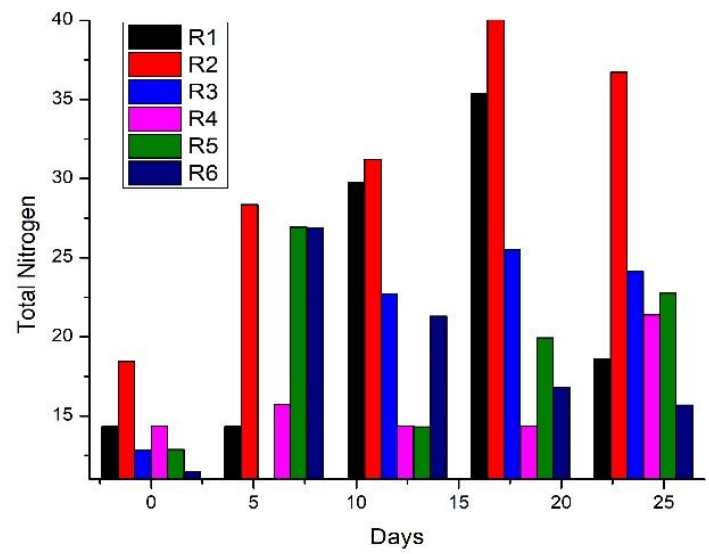

Variation of Total Nitrogen with days (with worms)

Fig. 7: Variation of $\mathrm{TN}$ in vermireactors (with worms).

and is a limiting factor in assessing compost maturity. The variation of nitrate nitrogen concentrations with and without worms along with the period of 24 days is shown in Fig. 11 and 12. Nitrate nitrogen increase in all vermireactors with an increase in the vermicomposting period. The highest nitrate nitrogen concentration was observed in R2 $(0.5823$ g. $\left.\mathrm{kg}^{-1}\right)$ in 24 days of composting. So, it can be predicted that $\mathrm{R} 2$ showed better quality compost with the higher $\mathrm{NO}_{3}{ }^{-}-\mathrm{N}$ content (Fig. 11).

\section{Phosphorus}

In this study, the available phosphorus was observed to increase as vermicomposting proceeds as shown in Fig. 13 (with worms) and Fig. 14 (without worms). An increase in phosphorus during vermicomposting was probably through mineralization and mobilization of phosphorous by the bacterial and fecal phosphatase activity of earthworms. Kaushik and Garg (2004) recorded a significant increase in total phosphorus and available-P after composting textile mill

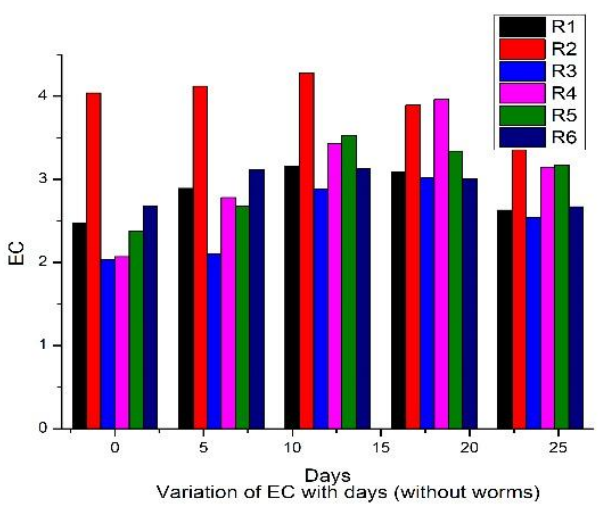

Fig. 6: Variation of electrical conductivity in vermireactors (without worms).

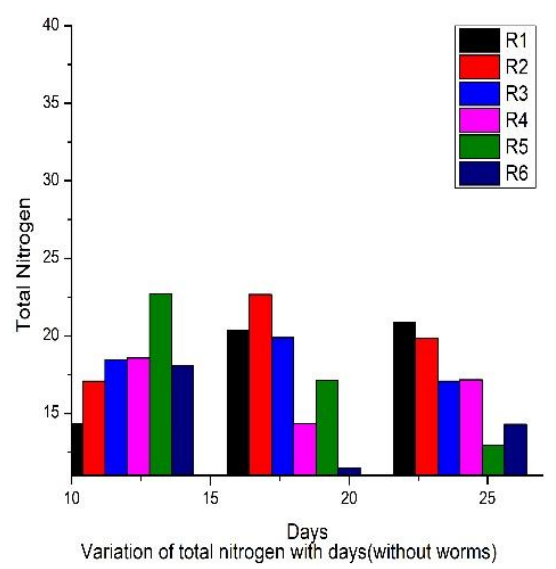

Fig. 8: Variation of TN in vermireactors (without worms).

sludge blended with cow dung and agricultural residues for 11 weeks. Phosphorus content was observed to increase in all vermireactors as vermicomposting proceeds. The highest phosphorus was observed in vermireactor R2.

\section{Earthworm Biomass}

The overall earthworm biomass showed a decline in 24 days of vermicomposting of CETP sludge with cow dung and sawdust. The vermireactor R1, R2, R4 contain the mixture of sludge and cow dung while vermireactor R3, R5, R6 contain the mixture of sludge, cow dung, and sawdust. The maximum earthworm biomass reduction was observed in vermireactor R1 which contains $8020 \%$ of sludge and cow dung. Earthworm biomass decreased in feed mixtures as sawdust proportion increases. The minimum earthworm biomass reduction was observed in vermireactor R2 which contains $5050 \%$ of sludge and cow dung respectively. The vermireactors which contain a mixture of sludge, cow dung, and sawdust show a more reduction in earthworm biomass as 


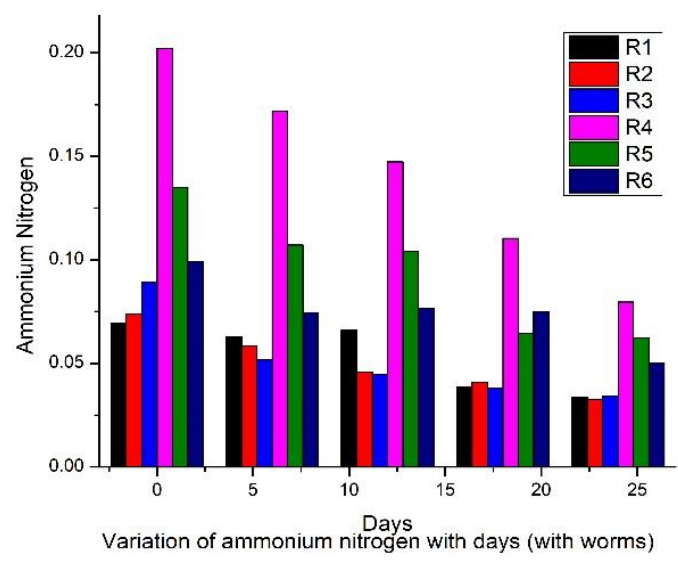

Fig. 9: Variation of $\mathrm{NH}_{4}{ }^{+}-\mathrm{N}$ in vermireactors (with worms).

compared to the vermireactors which contain the mixture of sludge and cow dung except for vermireactor R1.

\section{CONCLUSIONS}

The experimental results clearly indicate that vermicomposting

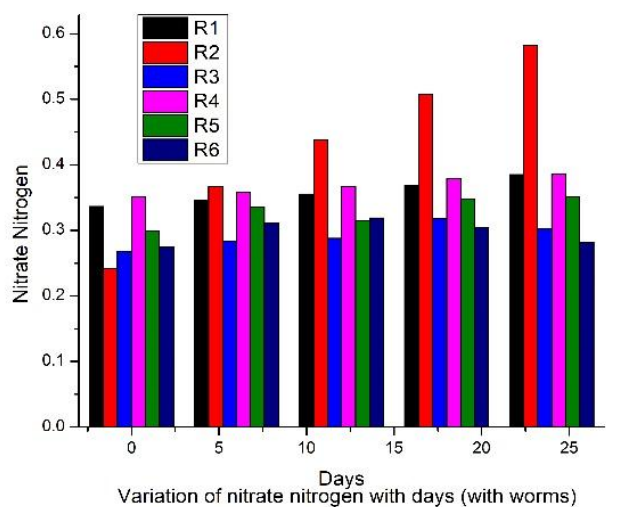

Fig. 11: Variation of $\mathrm{NO}_{3}{ }^{+}-\mathrm{N}$ in vermireactors (with worms).

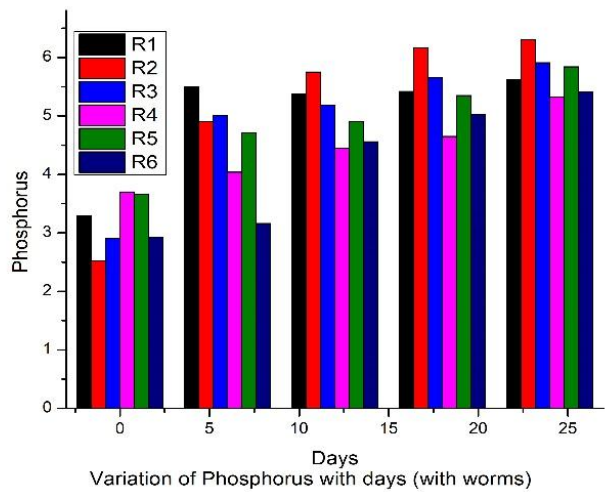

Fig. 13: Variation of phosphorus in vermireactors (with worms).

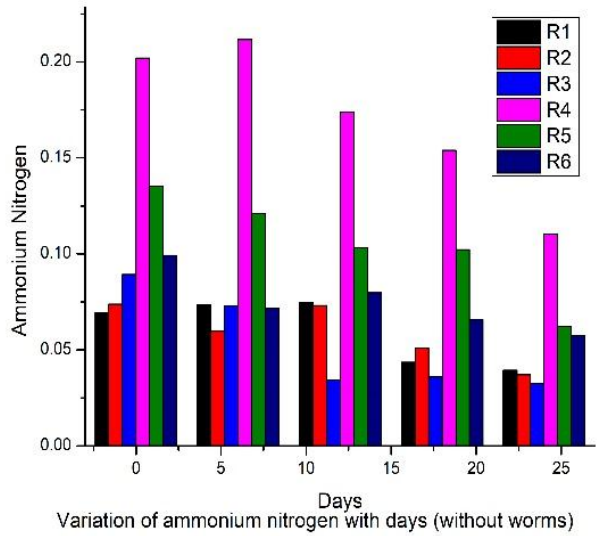

Fig. 10: Variation of $\mathrm{NH}_{4}{ }^{+}-\mathrm{N}$ in vermireactors (without worms).

may be used as a suitable technique to transform the sludge produced from a common effluent treatment plant. Physicochemical analysis of compost of various parameters like $\mathrm{pH}$, EC, total nitrogen, ammonium nitrogen, nitrate nitrogen, and phosphorus agreed with recommended standards. As ammonium concentration decreases and nitrate appears in

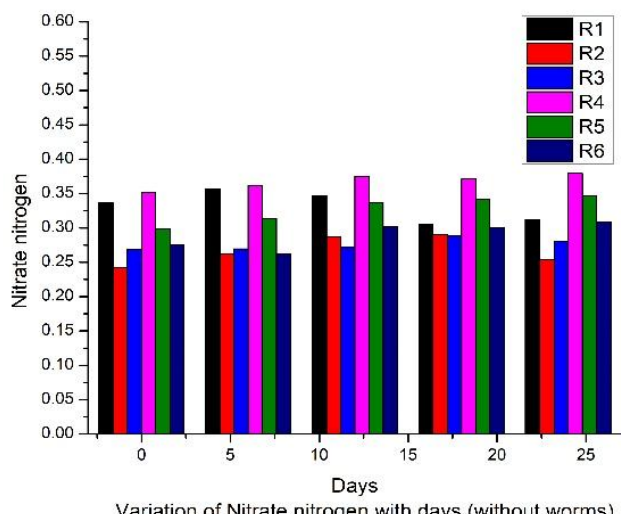

Fig. 12: Variation of $\mathrm{NO}_{3}{ }^{+}-\mathrm{N}$ in vermireactors (without worms).

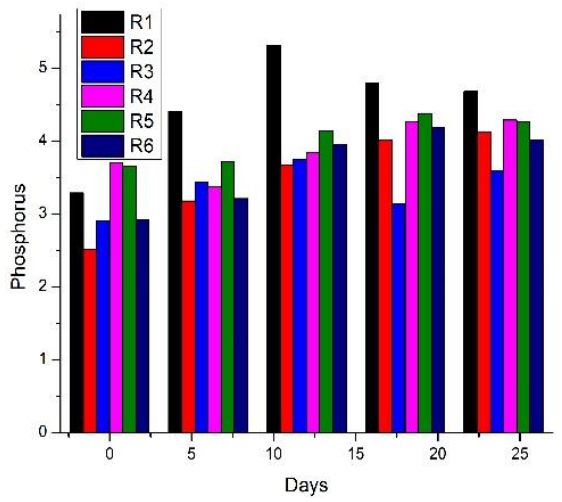

Fig. 14: Variation of phosphorus in vermireactors (without worms). 
composting material, it is considered to be used as suitable compost. The vermicomposting of CETP sludge produced a good quality of compost with $1.14 \%$ to $1.84 \%$ total nitrogen and $0.0541 \%$ to $0.063 \%$ phosphorus content. The maximum total nitrogen and maximum phosphorus content were observed in vermireactor R2. The values of all the studied parameters were found higher in vermireactors with worms in comparison to vermireactors without worms. The earthworm biomass was observed to decrease in all vermireactors due to the hazardous nature of sludge. The minimum reduction was observed in vermireactor R2 which contains $50 \%$ sludge and $50 \%$ cow dung, and maximum reduction was observed in vermireactor R1 which contains $80 \%$ sludge and $20 \%$ cow dung. So, it is concluded that based on physico-chemical parameters, vermicomposting of sludge produced from CETP is a more efficient method than the traditional composting techniques.

\section{ACKNOWLEDGMENT}

The authors are thankful to Director Malaviya National Institute of Technology Jaipur India for providing necessary research facilities.

\section{REFERENCES}

APHA, AWWA, and WEF 1999. Standard Method for the Examination of Water and Waste Water. Washington DC, 20th edition

Atiyeh, R.M., Lee, S., Edwards, C.A., Arancon, N.Q. and Metzger, J.D. 2002.The influence of humic acids derived from earthworm-processed organic wastes on plant growth. Bioresour. Technol., 84(1): 7-14.

Bantacut, T. and Aulia, A.N. 2019. Assessment of chemical oxygen demand balance for energy harvesting in sugar mills wastewater treatment. Nat. Env. \& Pol. Tech., 18(2): 413-423.

Begam, A. and Harikrishna 2010. Management of municipal sewage sludge by vermicomposting technique. Int. J. Chem. Technol. Res., 2(3): 1521-1525.

Bishop, P.L. and Godfrey, C. 1983. Nitrogen transformations during sludge composting. Biocycle, 24: 34-39.

Canelles, L.P., Olivares, F.L., Okorokova-Facanha, A.L. and Facanha, A.R. 2002. Humic acids isolated from earthworm compost enhance root elongation, lateral reemergence, and plasma membrane $\mathrm{H}^{+}$ATPase activity in maize roots. Plant Physiol., 130: 1951-1957.

Dominguez, J. and Edwards, C.A. 1997. Effects of stocking rate and moisture content on the growth and maturation of Eisenia andrei (Oligochaeta) in pig manure. Soil Biol. Biochem., 29: 743-746.

Edwards, C.A. 1995. Historical overview of vermicomposting. Bio Cycle, 36(6): 56-58.

Edwards, C.A. 1999. Interview with Dr. Clive Edwards-part two. Casting Call, 4(2): 3-7.

Edwards, C.A. and Arancon, N.Q. 2004. Interactions among organic matter, earthworms, and microorganisms in promoting plant growth.
In Magd, F. and Weil, R. (eds) Agro Ecosystems. CRC Press, Boca Raton, pp. 327-376.

Elvira, C., Goicoechea, M., Sampdro, L., Mato, S. and Nogales, R.1996. Bioconversion of solid paper-pulp mill sludge by earthworms. Bioresour. Technol., 75: 173-177.

Elvira, C. Sampedro, L., Benftez, E. and Nogales, R. 1997. Vermicomposting of sludges from the paper mill and dairy industries with Eisenia andrei a pilot-scale study. Bioresour. Technol. 63: 205-211.

Garg, V.K. and Kaushik, P. 2005. Vermistabilization of textile mill sludge spiked with poultry droppings by an epigeic earthworm Eisenia fetida. Bioresour. Technol., 96(9): 1063-1071.

Hirai, M. F., Chanyasak, V. and Kubota, H. 1983. A standard measurement for compost maturity. Biocycle, 24: 54-56.

Hemalatha, B. 2012. Vermicomposting of fruit waste and industrial sludge. Int. J. Adv. Eng. Technol., 3(2): 60-63.

Kalamdhad, A.S., Khwairakpam, M. and Kazmi, A.A. 2012. Drum composting of municipal solid waste. Environ. Technol., 33(3): 299-306.

Kaushik, P. and Garg, V.K. 2004. Dynamics of biological and chemical parameters during vermin-composting of solid textile mill sludge mixed with cow dung and agricultural residues. Bioresour. Technol., 94, 203-209.

Lee, K.E. 1992. Some trends opportunities in earthworm research or Darwin's children. The future of our discipline. Soil Biol. Biochem., 24: 1765-1771.

Maheshwari, S.M., Jethoo A.S., Vishvakarma, V.K., Khwairakpam, M. and Kriplani, P. 2019. Biodegradation of sludge produced from common effluent treatment plant (CETP) using drum composting technique. Nat. Environ. Pollut. Technol., 18(1): 231-236.

Neuhauser, E.F., Loehr, R.C. and Malecki, M.R. 1988. The potential of earthworms for managing sewage sludge. In: Edwards, C.A., and Neuhauser, E.F. (eds) Earthworms in Waste and Environmental Management. SPB Academic Publishing BV, The Hague, pp. 9-20.

Reinecke, A.J., Viljoen, S.A. and Saayman, R.J. 1992. The suitability of Eudrilus eugeniae, Perionyx excavatus, and Eisenia fetida (Oligochaeta) for vermicomposting in southern Africa in terms of their temperature requirements. Soil Biol. Biochem., 24(12): 1295-1307.

ROU, 2007. Literature Review of Worms in Waste Management: Recycled Organics Unit (Vol. 1. 2nd ed.). The University of New South Wales, Sydney, Australia.

Saradha, T. 1997. The culture of earthworms in the mixture of pond soil and leaf litter and analysis of vermifertilizer. J. Ecobiol., 9(3): 185-188.

Selladurai, G., Anbusaravanan, N., Prakash Shyam, K., Palanivel, K. and Kadalmani, K. 2009. Advances in Environ. Biol., 3(3): 278-284.

Sinha, R.K., Bharambe, G. and Chaudhari, U. 2008. Sewage treatment by Vermi filtration with the synchronous treatment of sludge by earthworms: A low-cost sustainable technology over conventional systems with potential for decentralization. The Environmentalist, 28: 409-420.

Suthar, S. 2009. Vermistabilization of municipal sewage sludge amended with sugarcane trash using epigeic Esenia fetida (Oligochaeta). J. Hazard. Mater., 163(1): 199-206

Tchobanoglous, G., Theisen, H. and Vigil, S. 1993. Integrated Solid Waste Management Engineering: Principles and Management Issues. McGraw Hill, Inc., New York.

Yadav, A. and Garg, V.K. 2009. Feasibility of nutrient recovery from industrial sludge by vermicomposting technology. J. Hazard. Mater. 168: 262-268.

Yadav, A. and Garg, V.K. 2011. Industrial waste and sludge management by vermicomposting. Rev. Environ. Sci. Biotechnol., 10(3): 243-276. 